\title{
Clemente Althaus y las Letras de Italia
}

\section{Por Estuardo Núñez}

En el recuento del proceso del romanticismo literario del $\mathrm{Pe}$ rú, está por hacerse la revisión crítica integral de sus más preclaros representativos. Entre ellos fué conspícuo poeta y dramaturgo Clemente Althaus (1835-1881). Para el estudio monográfico de su obra adelantamos estas notas acerca de su formación cultural, que nos revelan su honda afinidad con la cultura de Italia y las letras clásicas latinas.

En sus años de aprendizaje se incorporaron las esencias itálicas a través de su experiencia viajera por tierras de Italia y las lecturas de los grandes clásicos latínos 8 los modemos escritores italianos, J Al contacto iconleso realidad, y esos efluvios espirituales, se nutrio $\mathrm{y}$ engrandeció su genio creador, superando la simple imitación y cosntituyendo la obra poética original que ha legado y que con orgullo, puede exhibir la producción del roimanticismo. Otros espíritus de semejante formación intelertual caben igualmente dentro del romanticismo del Perú y se completaría por lo menos una trílogía de espíritus superdotados y nutridos de humanidades que fueron Pedro Paz Soldán (Juan de Aro* na), Manuel González Prada y Althaus. Arona tuvo igualmente la experiencia vivida de las letras y de la vida italiana, en la oportunidad de su prolongado viaje por Europa y Oriente, en que pudo pasar algún tiempo en la península. Pero lo detuvieron especialmente los estudios linguísticos latinos e italianos. Prada no tuvo ocasión de llegar nunca a Italia, pero desde París durante varios años, profundiza en el estudio de la lengua de Dante $y$ la versificación de los grandes poetas ítalianos. En cambio, Althaus armonizó con la vivencia italiana. El paiscije, la música, la pintura y las letras fueron sus pasiones desenvueltas en esa tierra 
acogedora e inolvidable. Lo retuvo en ella probablemente algún amor exaltado, de que dan fe sus encendidas estrofas. Su estilo de frase elegante, el buen gusto caracierístico, el equilibrio en la creación, su ponderada fluencia poética son cualidades fortalecídas en el contacto con los clásicos latinos e itálicos. Pero la virtud formativa de sus traducciones italianas puede explicarnos en conjunto su prestancia literaria y de ella poco o nada ha dicho la critica hasta hoy.

Clemente Althaus había hecho sus estudios secundarios en Santiago de Chile (entre 1846 y 1851). Alli tuvo maestros europeos que lo familiarizaron con los idiomas modernos y tal vez con el latín. Luego viajó por Europa entre 1855 y 1863 y tuvo oportuntdad de recorrer en su larga estada los países más importantes de ese continente. Podría reconstruirse por las fechas de sus composiciones, su posible itinerario europeo: Francia (1855-57), Inglaterra (1857), Italia (Nápoles, Roma, Florencia y Génova entre 1857 y 1859), España (Madrid y Cádiz, 1859-1860), Alemamia (1861 a 1862), y de nuevo Francia (de 1862-63). No hay duda de que su formación humanista fué un tanto desordenada y arbitraria, pero resulta evidente el impacto indeleble que dejan en él ciertas expresiones del arte europeo, y sobre todo, las manifestaciones del arte italiano. Para Althaus hay cosas buenas en este mundo que señalan sis predilecciones:

\section{para solaz y consuelonverso", \\ de los hombres infelices}

Hay el poema de Dante

y los de Homero sublimes.

y hay cuadros de Rafael

y hay música de Rossinl.

("Lo bueno de este mundo", 1866)

Su humanístico interés es múltiple. En la literatura, la poesía de Leopardi inspira su propia musa. Frente a los cuadros de Rafael le brotan varios poemas. En Madrid, su más intensa experiencia proviene de su contemplación de los cuadros de Ticiono. Coreggio le inspira notas admirativas tanto como el efluvio de las noches napolitanas. Y en lo musical, $\alpha$ Rossini (en 1855), después de haber oído por vez primera la plegaria del "Moisés", le dice entusiasmado: 
Por esa hora dichosa, por el celeste olvido

del mundo, de mi mismo, de mis males; por el alto placer que mi alma endiosa, a tu valor divino desiguales estos versos te envío agradecido ¡Oh delicia y amor de los mortales!

("A Rossini". 1855)

Es indudable que el país del Lacio dejó la más honda huella en su exquisito espíritu de creador. Sus lecturas, tal vez poco sistemáticas y más exaltadas y románticas, afianzaron no obstante una serena cultura clósica, que se percibe on su forma e inspiración interior $\mathrm{y}$ en los epígrafes de Horacio. En más de un poe ma, incluye glosas o intercala fragmentarias versiones de Virgilio y de Homero. Lo mismo hace con su predilecto Leopardi. Leía a los latinos en su lengua original y nutría su espíritu de los grandes italianos desde Petrarca y Dante hasta los modernos románticos como Guisti, Foscolo y Manzoni. Años después (1872) cuando reunió sus Obras poéticas (1) en vísperas de partir nuevamente a Europa (en 1876) para atender a su quebrantada salud y de donde no habría ya de volver, incorporó a su libro muchos poemas en que palpitalinconfunable la vivencialfialiana y en que se muestra un fervoroso admiradori del paisaje y del alma de Italia. En ese mismo libro definitivo incluyó como apéndice un discurso en prosa titulado "A Italia", que es muy revelador acerca de sus aficiones y de la profunda identificación que estableció con la vida italiana. Era Italia sin duda su segunda patria espiritual. Aparte de los temas de tal índole, incorpora igualmente a ese libro algunas "imitaciones" de cantos populares toscanos, en que se muestra además, cercano a la viva entraña del pueblo meridional y a la romántica devoción por la expresión folklórica. No descuida tampoco su homenaje o la referencia cálida dentro de sus poenas, a las grandes figuras clásicas de Italia, como en ese insigne soneto dedicado "Al Petrarca", que elogió sin reserva Menéndez y Pelayo.

Bajo el influjo de las corrientes humanísticas italianas, Clemente Althaus tradujo del latín algunos fragmentos bíblicos, que también incluye en el citado libro. Lo condujeron a ello clerta mística romántica inclinada a las expresiones de la sensibilidad oriental y su honda formación cristiana. Pero también actuó, sin duda, la tradición literaria del Perú que en diversas épocas había 
dado culto a las expresiones líricas insertas en la Biblia. Me refiero concretamente a las versiones peruanas de los Salmos que elaboraron en el siglo XVI, Miguel Cabello Balboa; en el siglo XVIII, Pablo de Olavide; en el siglo XIX, José Manuel Valdés y luego el propio Clemente Althaus. Las versiones bíblicas de este último poeta son las siguientes: "El lamento de David por la muerte de Saúl y Jonatós", que es traducción de la Elegía de David. inserta en el II Libro de Samuel, versículos 21-27. Traducción estricta son las tres primeras estrofas. Las tres siguientes constituyen una paráfrasis extensiva. Luego existen dos versiones del Salmo 136 "Super Flumina Babylonis". La primera, muy libre, con este mismo título, y la segunda, que constituye una paráfrasis, con el título "Cantos del Cautiverio".

Aún más que en sus versiones italianas, en estas bíblicas (que trasladó del latín) Althaus se aparta de la tendencia literal en su técnica de traducir y desembocaren una técnica "librista". Esto significa que en general, el texto original constituyó un apunte - impulso de partida para una ulterior elaboración personal. En el comienzo de los poemas la infención momifiesta es volcar el texto primigenio, pero en el desenvolvimiento posterior la imaginación del creador impera incontenible y se abre amplia realización de la propia inventiva. Con todo. Althans, no llegā a traicionar el tono particular de la lírica elegíaca hobrea ni la cristiana concepción de la vida que late tanto en to traducido como en lo inventado o parafráseado. Puccinelli Converso"

La más valiosa contribución de Althaus al conocimiento de la cultura italiana está integrada por la preciosa colecclón de verslones que tituló Sonetos ifalianos y que destaca entre la fronda romántica de traductores del siglo XIX. Sus Sonetos comprendieron tres series, aparecidas las dos primeras en el diario La Patria de Lima en 1873, y luego las tres series completas en El Comercio de Lima en 1874, con algunas variantes que anotaremos en el texto de dichos sonetos. En la primera serie, dedicada a Petrarca, figuran 9 sonetos de este autor, a saber: 1) "Recuerda que el viernes santo fué el día que conoció a Laura", 2) "Belleza de Laura", 3) "Vergüenza amorosa", 4) "En presencia de Laura no puede hablar, ni llorar ni respirar", 5) "La noche y la curora", 6) "Laura en el cielo", 7) "Volviendo a Valclusa años después de la muerte de Laura", 8) "En la muerte de Sennucio, poeta y amante", B) "A un paiarillo". 
Las versiones itálicas de Althaus denotan una virtud significativa al mostrar una personal predilección : el soneto. Los románticos trataron como todas das escuelas literarias desde el Renacimiento en España y desde el siglo XIII en Italia, patria honrosa del soneto, de dar nuevo culto a esta tradicional y exquisita forma literaria. Fue aquella, por lo demás, una actitud común a lodos los románticos a que se refiere Walter Mönch, en su historia del soneto, contando la anécdota de Guillermo de Humboldt que se propuso cultivarlo intensamente y escribió cada día un soneto entre 1832 y hasta pocas semanas antes de morir en 1835, acumulando así, alrededor de 1200 sonetos, como producto de esa obsesión característica. Althaus se incorpora de esta suerte al conjunto de los poetas peruanos que desde el siglo XVI, con Garcés y Dávalos como cimientos y con Xavier Abril, Martín Adán y otros representativos de las últimas generaciones como coronación, dan lustre a la serena $\mathrm{y}$ armónica arquitectura de una historia del soneto en el Perú que aún está por escribirse.

Es interesante confrontar las versiones petrarquianas hechas en el Perú en el siglo XIX con las producidas aqui mismn por Enrique Garcés, en pleno siglo XVI.

Garcés, escritor y minero nacido en Portugal, produjo como es sabido, una versión completa de Los Sonetos y Canciones, durante su larga estadacencel Perúcentre 1547 \$ 1589, lapso en que vivió y laboró comg arbitrista, minero y poeta, entre Huancavelica, Potosí, Huamanga y Lima. Su versión de Petrarca apareció en Madrid en 1591 (2). Tradujo, además, (del portugués) Los lustacas de Camoens y una obra de Patrizzi (del latín). Resulta interesante comparar las versiones de los mismos poemas de Petrarca por un escritor del Renacimiento como Garcés, y por uno del Romanticismo como Althaus, producidas en los extremos de un lapso de casi tres siglos que media entre unas y otras, por lo que nos puede ilustrar acerca de la técnica de traducción empleada y la distinta sensibilidad de sus respectivos autores. Dos estilos diferentes se contraponen. En el renacentista, dominante la clegoría y la fantasía mitológica, de fina estirpe clásica, se advierte el afán literal. En el romántico, se enseñorea la fluencia sentimental, la adaptación al gusto contemporáneo, y aunque hay desen de mantener la fidelidad, el ímpetu creador avasalla el propósito inicial, y desemboca por momentos francamente en una traducción libre. Althaus lleva la ventaja de conocer profundamente su propia lengua, en tanto Garcés (de lengua materna portuguesa) en- 
cuentra a veces dificultades de léxico que sólo salva a medias, o traicionando el genio idiomático. Pero, en veces, la fortuna acompaña a Garcés, quien supera a Althaus, como en la versión del Soneto 260: (3).

Valle, che de' lamenti miei se' piena;

Fiume, che spesso del mio pianger cresci;

Fere silvestre, vaghi augelli e pescl.

Che l' una e l' altra verde riva affrena:

Aria de' miei sospir calda e serena:

Dolce sentier, che si amaro riescl;

Colle, che mi piacesti, or mi rincresci,

Ov' ancor per usanza amor mi mena;

Ben rịconosco in voi $\mathrm{l}^{\prime}$ usate forme, Non, lasso, in me; che da si lieta vita Son fatto albergo d' infinita doglia.

Quinci vedea'l mio bene, e per quest' orm $\theta$ Torno a veder ond al ciel nuda é gita Lasciando in terra la sua bella spoglia.

Veamos seguidormentel la versión de Garcés:

Valle que de mis llantoseres Heno rSO" Río, que dellos tomas más augmento, Pesces, aues, y fieras, qu' el assiento

En tal Jugar teneis, y tan ameno.

Ayre con mis sospiros mós sereno. Senda dulce, que amarga agora siento, Collado que otro tiempo gran contento Me dauas, con quien tanto agora pueno:

En vosoiros conosco lo passado, Mas en mi no, que de vna dulce vista Aluergue soy tornado de amargura.

De aqui via yo mi bien, de donde es ida Desnuda al cielo en passo apressurado, Dexando acá su linda vestidura. 
Y finalmente la traducción de Althaus:

¡Oh valle, donde mi lamento suena, Río que tanto con mi lloro creces, Silvestres flores, vagas aves, peces, que la una y la otra verde orilla enfrena

Aura de mis suspiros toda llena, Dulce senda que amarga hoy me pareces, Alcor que me alegraste tantas veces $Y$ ahora me causas tan profunda penal

Todos sois lo que fuisteis, todavía; No yo jay de míl que tan feliz he sido $Y$ soy albergue de infinito duelo:

Ahl aquí fué donde $\mathrm{mi}$ bien vivía, Y desde aquí a los cielos ha subido, Dejando al mundo su terrestre velo.

Si la palma ha sido en esta versión para Garcés, no obstante lo discutido de su estro poético $\mathrm{y}$ de su buen dominio del idio$\mathrm{ma}$, el acierto es del romántico Althaus en este otro Soneto، el 69, que en italiano dico lioteca. de Letras

Erano i capes d lofo alel dufo spars 0 "

Ch 'n mille dolci nodi gli avvolgea :

$E^{\prime}$ l vago lume oltra misura ardea

Di quei begli occhi ch' or ne son si scarsi;

E' l viso di pietosi color farsi

Non so se vero o falso mi parea:

I' che l' esca amorosa al petto avea,

Qual maraviglia, se di subit' arsi?

Non era l' andar suo cosa mortale,

Ma d'angelica forma; $\theta$ le parole

Sonaba altro, che pur yoce umana.

Ino spirto celeste, u nvivo Sole

Fu quel $\mathrm{ch}^{\prime} \mathrm{i}^{\prime}$ vidi: e se non fosse or tale;

Piaga perallentar d' arco non sana 
Garcés lo traslada en esta forma, un tanto forzada y $\sin$ fluencic:

Aquel cabello de oro era esparzido all aura, que en mil ñudos le enlazaua, y la luz en estremo relumbraua del Sol, que de mi suele andar huydo.

Mostrauase me el rostro enternescido No see si de verdad, o me engañaua, Pues si en $\mathrm{mi}$ seno yesca tal estaua Que hay qu' espantar de verme ansi encendidol

Su contoneo no erá acá del suelo, $Y$ su boz se mostraua mas que humana, vn Anqel parescia en el asseo.

Un biuo sol, vn noscé que del Cielo, $Y$ aunque algo menos fuera (que no creo) No porqu' 1 arco afloxe llear fama.

Paro Althausilogrio unac cuiddedosa Q talada versión:

Volaba la dorada cabellera

Al aura que en mil nudos la envolvía $Y$ de los ojos el fulgor ardía, Como el sol en mitad de su carrerc.

De su piedad, o falsa o verdadera En el color su rostro se teñía: Yo que al amor dispuesto me sentín ¿Qué mucho fué que de improviso ardiera.

No era su leve andar humana cosa, sino de forma angélica y volante; No mortal parecía, sino diosa:

$\mathrm{Y}$ al mirarla así sola semejante por lo bella, modesta y pudorosa, Yo ser juraba u inmortal amante. 
De la labor traductora de Garcés nos ha ofrecido aportes considerables en los últimos tiempos la nueva crítica y los investigadores del pasado colonial del Perú, pero de las versiones petrarquinas de Althaus no teníamos información alguna. La publicación de sus Sonetos italianos abre una insospechada pers. pectiva tanto para conocer el fondo cultural de una generación y específicamente la formación italiana de Althaus, como para estudiar la "fortuna" del gran poeta aretino en América. El nombre de Althaus se incorpora a la exigua lista de los insignes traductorees de Petrarca en el Nuevo Mundo. Pero volvamos al examen del resto de sus Sonetos italianos y a la apreciación global de los mismos.

En la segunda serie, incluye Althaus 3 sonetos de Dante, a saber, "A Guido", "Saludo a Beatriz" y "Alabanza de Beatriz"; 2 sonetos de Ariosto, o sean: "A una estancia donde esperaba $a$ su amada" y "La cabellera cortada"; 2 sonetos de Miguel Angel Buonarroti titulados "A Victoria Colonna" y "Desengaño" y, finalmente, 2 sonetos de la propia Victoria Colonna: "Al Cardenal Bembo" $y$ "Recuerdos de su esposo"; en total también 9 composiciones traducidas.

En la tercera serie, se recogen las versiones de sonetos del Cardenal Pietro Bembo (1470-1547) "A Italia" y de Torcuato Tasso (1544-1595) "A San Francislo de Asís" y l'Compara su amada a la aurora"; de "Vicenzo Monti (1754-1828) "A una doncella que profesaba" y "En otra profesión"; de Vicenzo da Filicaia (16421704) "A Italia"; de Hugo Foscolo (1778-1827) "A mi hermano" y "A la amada", y por último, un soneto de Giuseppe Giusti (1809. 1850) titulado "Los 35 años". Totaliza esta serie igualmente 9 sonetos, con lo cual tenemos en las 3 series 27 sonetos.

El autor de las versiones se esforzó por mantener la fidelidad al original, orillando un tanto la tendencia general de los traductores romónticos de hacer versiones libérrimas. Pero en A. thaus $y$ en su propia poesía, dominó siempre una tónica clásica que también informa sus traslados. En medio del logrado valor literario de estas versiones, cabría formular un reparo: la fuerte personalidad literaria del traductor se ha impuesto demasiado, al punto que todos los sonetos traducidos se parecen entre sí en el tono y estilo y resultan, al parecer más obras de Althaus que de sus respectivos autores. De otro lado, los culores clásicos y románticos traducidos sienten y se expresan al unísono, y las versiones no se han cuidado de mantener el "aire" personal de cada 
cutor. La técnica de su modelado paciente y castigado, demos trada con las variantes que se anotam en las dos publicaciones de 1873 y 1874, con sólo pocos meses de diferencia, acabó por esfumar el carácter de cada autor traducido, aunque, al mismo tiempo, demuesira en Althaus a un verdadero orfebre de la palabra $y$ a una extraordinaria capacidad en el oficio literario.

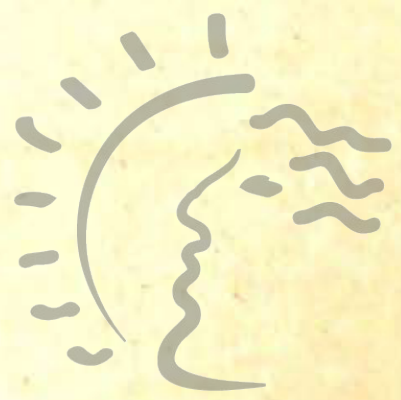

\section{Biblioteca de Letras} "Jorge Puccinelli Converso" 